\title{
Differential recruitment of Dishevelled provides signaling specificity in the planar cell polarity and Wingless signaling pathways
}

\author{
Jeffrey D. Axelrod, ${ }^{2,5}$ Jeffrey R. Miller, ${ }^{1,3}$ Joshua M. Shulman, ${ }^{1,4}$ Randall T. Moon, ${ }^{1,3}$ \\ and Norbert Perrimon ${ }^{1,2}$ \\ ${ }^{1}$ Howard Hughes Medical Institute, ${ }^{2}$ Department of Genetics, Harvard M edical School, Boston, Massachusetts 02115 USA; \\ ${ }^{3}$ Department of Pharmacology, University of Washington School of M edicine, Seattle, Washington 98195 USA
}

In D rosophila, planar cell polarity (PCP) signaling is mediated by the receptor Frizzled (Fz) and transduced by Dishevelled (Dsh). Wingless (Wg) signaling also requires Dsh and may utilize DFz2 as a receptor. Using a heterologous system, we show that Dsh is recruited selectively to the membrane by Fz but not DFz2, and this recruitment depends on the DEP domain but not the PDZ domain in Dsh. A mutation in the DEP domain impairs both membrane localization and the function of Dsh in PCP signaling indicating that translocation is important for function. Further genetic and molecular analyses suggest that conserved domains in Dsh function differently during PCP and Wg signaling and that divergent intracel lular pathways are activated. We propose that Dsh has distinct roles in PCP and Wg signaling. The PCP signal may selectively result in focal Fz activation and asymmetric relocalization of Dsh to the membrane, where Dsh effects cytoskeletal reorganization to orient prehair initiation.

[Key Words: Dishevelled; planar cell polarity; signaling; Frizzled; DEP domain; tissue polarity]

Received April 9, 1998; revised version accepted June 17, 1998.

Drosophila Dishevelled (Dsh) was initially identified for its role in transducing the planar cell polarity (PCP; al so known as tissue polarity) signal in developing imaginal disc epithelia (Adler 1992; Gubb 1993; Eaton 1997; Shulman et al. 1998). Dsh was shown subsequently to transduce an additional signal mediated by Wingless (Wg) (Klingensmith et al. 1994). We have investigated how Dsh functions in PCP signaling and whether it has the same or different function in Wg signaling.

PCP signaling controls the polarity of epithelial cells within a plane orthogonal to their apical-basal axis. One manifestation of this cellular polarity is the oriented organization of trichomes (cell hairs). In wild-type flies, the cell hair arising from each cell's distal vertex contributes to a parallel and specifically oriented array (Fig. 5A, below). Mutations in dsh, as well as additional genes including frizzled (fz), prickle (pk), inturned (in), fuzzy (fy), multiple wing hairs (mwh), and others all disrupt the polarity of the trichomes. The resulting mutant phenotypes include swirls and distortions of the hair polarity pattern, and in some instances, more than one trichome

\footnotetext{
${ }^{4}$ Present address: Wellcome/CRC Institute, Cambridge CB2 1QR, UK. ${ }^{5}$ Corresponding author. Present address: Department of Pathology, Stanford University School of Medicine, Stanford, California 94305 USA. E-MAIL jaxelrod@cmgm.stanford.edu; FAX (650) 725-6902.
}

per cell (e.g., Fig. 5B, below). A putative signal transduction pathway has been proposed (Krasnow et al. 1995), which serves to polarize cells, allowing them to distinguish one side of the cell from the other, and to propagate this information from cell to cell. In this pathway, Fz, a seven-transmembrane protein (without apparent primary sequence homology to the G-protein-coupled receptors) acts as a receptor (Vinson et al. 1989; Adler et al. 1990), functioning upstream of Dsh. Dsh then antagonizes the activities of Fy, In (both novel transmembrane proteins; Park et al. 1996; Collier and Gubb 1997), and Mwh, which are in turn proposed to regulate the cytoskel etal apparatus responsible for control of PCP. M utations in RhoA affect this process (Strutt et al. 1997), and experiments with dominant-negative mutants have implicated Cdc42 and Rac1 (Eaton et al. 1995, 1996) as additional effectors. $\mathrm{Pk}$ is proposed to function either in transmission of the signal to adjacent cells, or in interpretation of the directionality of the signal. Thus far, no ligand for the PCP pathway has been identified. Although a tentative signal transduction pathway has been proposed, the mechanism by which asymmetry is established in the responding cells is not understood.

In addition to transduction of the PCP signal, Dsh is required for $\mathrm{Wg}$ signal transduction (Perrimon and $\mathrm{Ma}$ howald 1987; Klingensmith et al. 1994; Miller and Moon 
1996). Wg, a member of the Wnt family, is a secreted glycoprotein that mediates a variety of cell fate choices throughout Drosophila development (Cadigan and N usse 1997). The current model for Wg signaling proposes that in the absence of $\mathrm{Wg}$ signal, Zeste-white3 (Zw3, also known as Shaggy), a serine/threonine kinase homol ogous to GSK3, phosphoryl ates Armadillo (Arm, a homolog of $\beta$-catenin), destabilizing the cytoplasmic form of the protein. In the presence of $\mathrm{Wg}$, the receptor acts through Dsh to antagonize Zw3 activity, and Arm is stabilized, resulting in its interaction with Pangolin (Pan, a TCF/Lef1-type transcription factor), forming a stable transcriptional regulator that can be seen in the nucleus. Based on cell-culture assays, Drosophila Frizzled2 (DFz2) has been proposed to encode the Wg receptor (Bhanot et al. 1996), al though confirmation awaits more definitive evidence. This observation also raises the possibility that another member of the Wnt family, of which four have been identified in Drosophila, could function as the PCP ligand to regulate Fz activity.

Wnt signaling appears to be highly conserved. A large family of Wnt proteins has been identified in various species, and many have been shown to act in signaling events (C adigan and N usse 1997). An extensive Fz family has al so been identified that might function as receptors for Wnts (Orsulic and Peifer 1996), and mice and humans express multiple Dsh proteins (Sussman et al 1994; Klingensmith et al. 1996; Sokol et al. 1996; Tsang et al. 1996; Semenov and Snyder 1997). Wnts have been divided into at least two functional classes on the basis of their ability or fai lure to induce transformation of certain cultured mammalian cells (Wong et al. 1994). In Xenopus, members of the Wntl class have been shown to induce axis duplication and to function in a pathway similar to the Wg signaling pathway (M oon et al. 1997). In contrast, members of the Wnt5a class fail to induce axis duplication but, instead, alter morphogenetic movements during gastrulation (M oon et al. 1993, 1997). Whereas the Wnt1 class corresponds to Drosophila Wg in its signaling mechanism, it is unclear if the Wnt5a class corresponds to the PCP signaling mechanism.

Drosophila Dsh is a modular protein of unknown function that is well conserved in relation to its vertebrate homol ogs (Klingensmith et al. 1994; Thiesen et al. 1994). Alignment of family members reveals three conserved domains. The first, a DIX domain, is similar to a domain in murine Axin, a recently described modulator of the Wnt1 pathway (Zeng et al. 1997). The second contains a PDZ domain (Ponting et al. 1997); PDZ domains recognize and bind short motifs at the carboxyl termini of proteins (but may bind other motifs as well). PDZ domains can al so form dimers. The third domain, called $D E P$, is conserved among a set of proteins that have in common the ability to regul ate various GTPases, including both heterotrimeric $\mathrm{G}$ proteins and Ras-like small GTPases (Ponting and Bork 1996).

Here, we address how Dsh mediates the PCP signal and ask if this activity is distinct from its role in $\mathrm{Wg}$ signaling. We demonstrate that Dsh is recruited from the cytoplasm to the membrane and to filopodia by the PCP receptor, Fz, and that this rel ocalization is important for PCP signaling. The DEP domain is required for membrane localization of Dsh and is the site of a mutation that specifical ly disrupts PCP signaling. In contrast, the putative $W g$ receptor $D F z 2$ fails to induce Dsh relocalization, and the DEP domain is not critical for Wg signaling. Finally, genetic and molecular assays suggest that Dsh makes distinct protein contacts in its two roles. We propose that membrane local ization of Dsh mediates an asymmetric subcellular signal to direct a polarized response to the PCP signal.

\section{Results}

Localization of Dsh to the membrane and to filopodia in response to $\mathrm{Fz}$

Of the known components of PCP and $\mathrm{Wg}$ signaling, Drosophila Dsh is thought to act most immediately downstream of the receptor. We were therefore interested in examining possible interactions between Dsh and the PCP receptor $\mathrm{Fz}$ and the putative $\mathrm{Wg}$ receptor $D F z 2$. The sequences of these proteins suggested the possibility of a direct interaction. Dsh contains a PDZ domain, though it differs from the consensus by lacking a conserved basic residue at position 257 (M orais Cabral et al. 1996). DfZ2 has the consensus PDZ recognition peptide SXV at its carboxyl terminus (Bhanot et al. 1996), but Fz terminates with the sequence AXV (Vinson et al. 1989), which although similar, has not been shown to bind PDZ domains.

We chose to test whether either Fz or DFz2 could recruit Dsh to the membrane, perhaps via the PDZ motif, by introducing these components into a heterologous system that is rapid, allows controlled expression of multiple proteins, and is amenable to analyzing the intracellular distribution of proteins. mRNAs encoding Fz or DFz2 and a fusion of Dsh to green fluorescent protein (Dsh-GFP) were synthesized in vitro and injected into Xenopus embryos at the four-cell stage. Animal caps from stage 9 embryos were dissected to reveal the blastocoelar cells, which were examined by confocal microscopy as described previously (Yang-Snyder et al. 1996).

We first examined the relationship between Dsh-GFP and Fz. Dsh-GFP, when introduced alone, is observed predominantly in association with cytoplasmic vesicles (Fig. 1A). By comparison, in Drosophila, Dsh is observed to be cytoplasmic but shows a vesicular pattern in latestage embryos (Yanagawa et al. 1995). In third instar imaginal discs, Dsh is al so cytoplasmic, but pupal-stage discs have not been examined. We have noted previously that upon overexpression in cultured Drosophila S2 cells, Dsh also local izes to cytoplasmic vesicles (A xel rod et al. 1996). When $\mathrm{Fz}$ is expressed simultaneously with Dsh-GFP, Dsh-GFP shows a qualitative redistribution to the membrane or cell cortex (Fig. 1B-D). Under these conditions, we also noticed localization of Dsh-GFP to filopodia present on the blastocoelar (free) surfaces of the animal cap cells (Fig. 1E-G). Staining with phalloidin (and Dsh-GFP) revealed that the filopodia contain filamentous actin (Fig. $1 G^{\prime}$ ). It is interesting to note that 

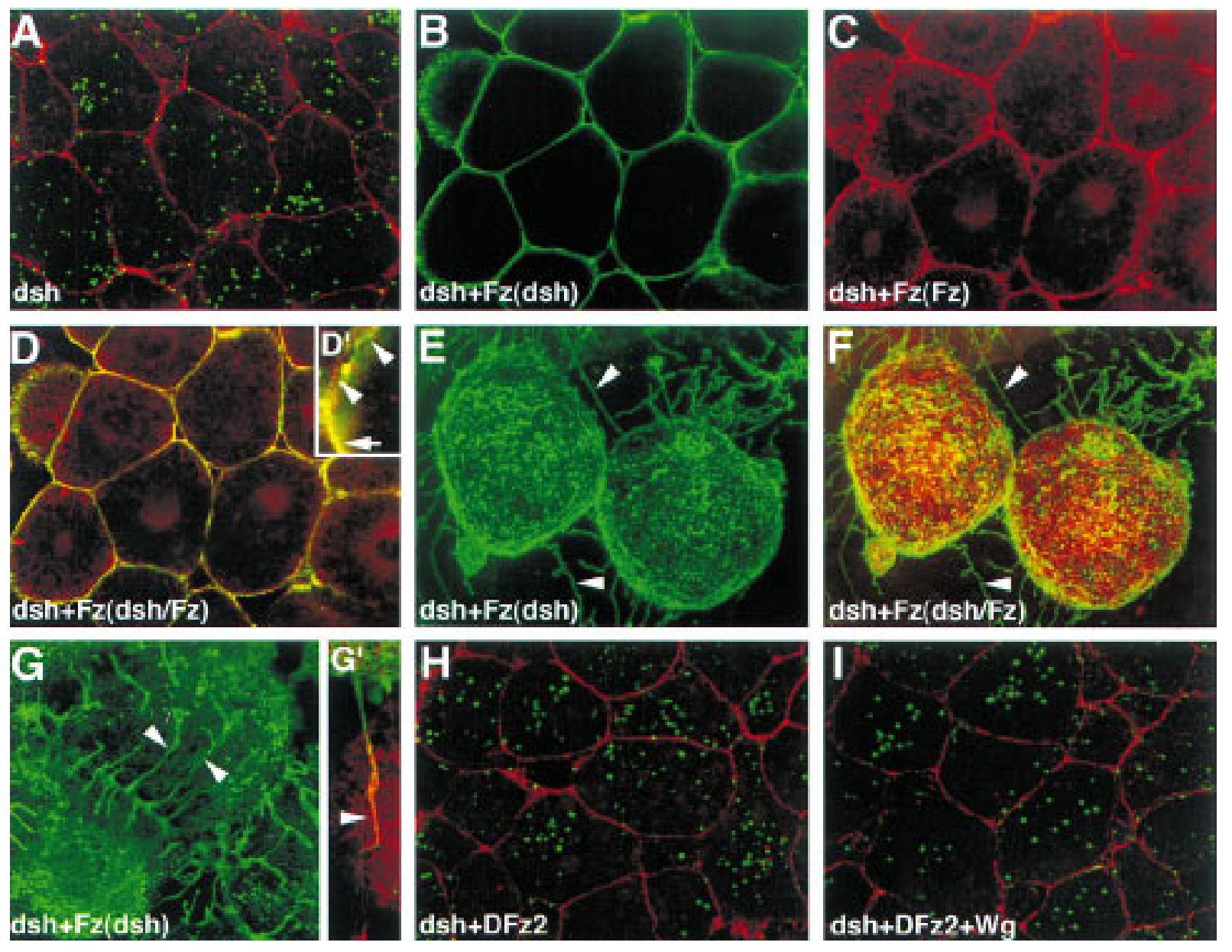

Figure 1. Dsh-GFP localizes to the membrane and filopodia in response to Fz in Xenopus animal cap cells. (A) Dsh-GFP (green) Iocalizes in the cytoplasm in an apparent association with intracellular vesicles (Texas Red phalloidin Iabels the cell cortex). (B) In response to Fz, Dsh-GFP redistributes to the plasma membrane. (C) Fz localizes predominantly to the plasma membrane in the presence (shown) or absence (not shown) of Dsh-GFP. (D, D') Dsh-GFP colocalizes with Fz at the plasma membrane. Yellow staining represents colocalization of Dsh-GFP (green from B) and Fz (red from C) and is marked by an arrow in D'. However, regions of the plasma membrane are also stained only by Dsh-GFP or Fz, demonstrating that the colocalization of Dsh-GFP and Fz is not absolute (arrowheads in $D^{\prime}$ ). (E-G) In response to Fz, Dsh-GFP al so accumulates in filopodia that extend from the free surface of the animal cap cells (arrowheads). These filopodia contain actin (stained with phalloidin; arrowhead in G') but lack Fz (note lack of yellow staining in filopodia in F). $(\mathrm{H}, \mathrm{I})$ In contrast to the effects of Fz on the localization of Dsh-GFP, neither DFz2 $(\mathrm{H})$ nor the combination of DFz2 and $\mathrm{Wg}(\mathrm{I})$ results in a change in the localization of Dsh-GFP (Dsh-GFP =green). Texas Red phalloidin was used to visualize cell outlines in $\mathrm{A}, \mathrm{H}$, and $\mathrm{I}$, and the filopodium in $\mathrm{G}^{\prime}$.

although the filopodia stain with Dsh-GFP, little or no Fz localizes there, and that at the cell cortex, the Fz and Dsh-GFP show imperfect colocalization (Fig. 1D'). Fz staining is local ized predominantly to the plasma membrane, and to a lesser extent to intracel lul ar membranes (probably ER and/or Gol gi) in these cells (Fig. 1C,F). This suggests that, whereas Fz may induce localization of Dsh-GFP to the membrane and filopodia, it may do so by a mechanism other than direct binding.

Dsh domain requirements for Fz-dependent relocalization

To test whether recruitment of Dsh-GFP to the membrane by $\mathrm{Fz}$ depends on an interaction between the Dsh
PDZ domain and the carboxy-terminal AXV of FZ, we used the Xenopus animal cap assay to test for localization of a Dsh construct from which the PDZ domain and the basic domain had been deleted [Dsh( $\triangle$ bPDZ)-GFP, Fig. 6, below]. Strikingly, in the presence of $F z$, Dsh( $\triangle \mathrm{bPDZ})$-GFP localizes to the membrane and to filopodia in a manner indistinguishable from intact DshGFP (Fig. 2A,B). Similarly, a Fz lacking the carboxy-terminal $A X V$ retains its ability to induce membrane localization of Dsh-GFP (not shown). These results argue that recruitment of Dsh-GFP to the membrane occurs by a mechanism not requiring the Dsh PDZ domain or a potential PDZ target peptide in Fz.

Because the PDZ domain appears to play no role in the relocalization of Dsh in response to $\mathrm{Fz}$, we tested the 
requirements for the other conserved domains in this response. When a construct carrying a deletion of the DIX domain (Fig. 6, below) was tested as above, we noted that in the absence of exogenous Fz protein, Dsh $(\Delta \mathrm{DIX})$ GFP did not associate with cytoplasmic vesicles, but instead was distributed uniformly throughout the cytoplasm, and some appeared to localize at the membrane (Fig. 2C). In the presence of Fz, Dsh( $\Delta$ DIX)-GFP relocalized to the membrane and to filopodia as does the wildtype protein (Fig. 2D). We conclude that the DIX domain contains sequences necessary to anchor Dsh to the cytoplasmic vesicles. The nature and significance of these vesicles are unknown, though they appear not to be insoluble, improperly folded Dsh, as the Dsh-GFP fluoresces and can be mobilized to the membrane in the presence of Fz.

We next tested the requirement for the DEP domain. Dsh( $\triangle D E P)-G F P$ (Fig. 6, below) is seen in association with cytoplasmic vesicles in the absence of $\mathrm{Fz}$, and is indistinguishable from wild-type (Fig 2E). However, when Fz is coexpressed, Dsh( $\triangle D E P)-G F P$ fails to rel ocal- ize to the membrane or to filopodia, but instead remains associated with the cytopl asmic vesicles (Fig. 2F). Therefore, the DEP domain is required for the relocal ization of Dsh in response to Fz. Finally, we asked whether the DEP domain is sufficient to cause relocalization of Dsh to the membrane. Dsh(DEP+) (Fig. 6, below) is cytoplasmic in the absence of $F z$, as expected, because it lacks the DIX domain (Fig. 2G). In the presence of Fz, Dsh(DEP+) relocalizes to the membrane (Fig. $2 \mathrm{H}$ ), demonstrating that the DEP domain is sufficient to relocalize Dsh in response to $\mathrm{Fz}$.

$\mathrm{dsh}^{1}$, a mutant that is functional for Wg but not PCP signaling

$\mathrm{dsh}^{1}$ is an allele that behaves as a genetic null for PCP signaling, but is fully functional for Wg signaling (Perrimon and Mahowald 1987). dsh ${ }^{1}$ might encode a promoter or enhancer mutation, such that levels of Dsh might be produced that are sufficient to sustain Wg signaling, but not PCP signaling. In contrast, we hypothesized that $\mathrm{dsh}^{1}$ might encode a structural mutation, in-
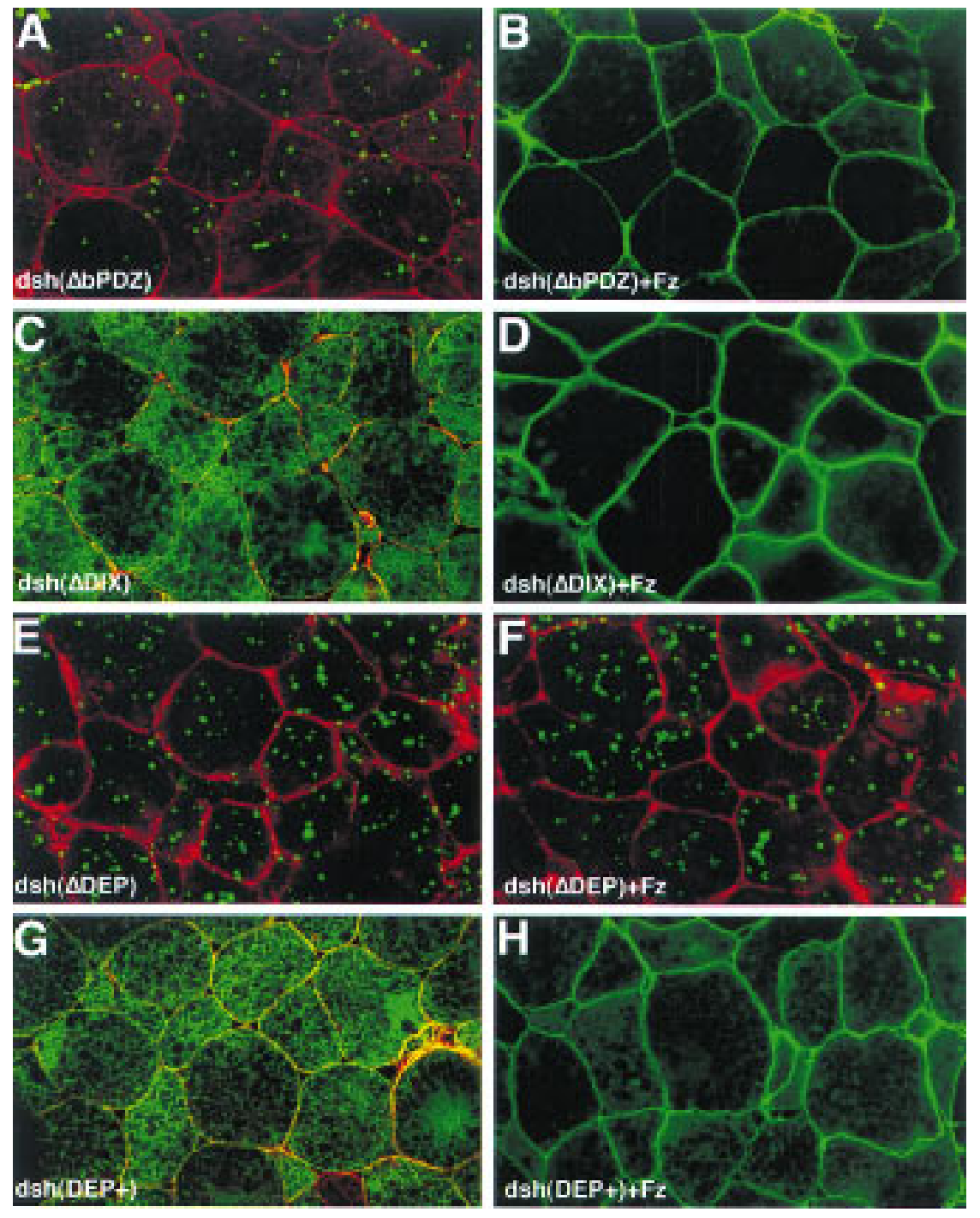

Figure 2. Analysis of Dsh domains required for Fz-dependent relocalization of Dsh in Xenopus animal cap cells. (A) Dsh( $\triangle$ bPDZ)-GFP localizes to the cytoplasm in a punctate pattern. (B) In response to Fz, Dsh( $\triangle \mathrm{bPDZ})-\mathrm{GFP}$ relocalizes to the plasma membrane (shown) and is also present in filopodia (not shown). (C) Dsh( $\triangle D I X)-G F P$ does not display a punctate pattern and instead is distributed diffusely throughout the cytopl asm (but is excluded from yolk granules). (D) In response to $F z, D s h(\Delta D I X)-G F P$ relocalizes to the plasma membrane (shown) and is al so present in filopodia (not shown). (E) Dsh(DDEP)-GFP localizes to the cytoplasm in a punctate pattern. (F) Dsh( $\triangle D E P)-G F P$, however, does not relocal ize to the plasma membrane in response to Fz and displays a punctate pattern similar to that seen in the absence of Fz. (G) $\mathrm{Dsh}(\mathrm{DEP}+)$ is diffusely cytoplasmic in the absence of $\mathrm{Fz}$, and is sufficient to promote membrane localization in the presence of Fz $(H)$. Texas Red phalloidin was used to visualize cell outlines in A, C, E, and G. 
dicating a differential activity of Dsh in the two pathways. We therefore cloned the dsh ${ }^{1}$ allele, and found a single amino acid substitution of $\mathrm{M}$ for $\mathrm{K}$ at position 417 (Fig. 3). This residue is conserved among the dsh homologs so far isolated, and is conserved moderately among the recognized DEP domains. To verify that this substitution confers the dsh ${ }^{1}$ phenotype, this mutation was created in a wild-type genomic DN A fragment, Pelement transformants were created, and these were used to rescue dsh null mutant flies. The rescued flies were viable and had the dsh ${ }^{1}$ phenotype; this was independent of the copy number of the transforming gene, from one to three copies (not shown). Thus, a single amino acid substitution in the DEP domain of Dsh confers a loss of function for PCP signaling, yet the mutant protein is functional for $\mathrm{Wg}$ signaling.

\section{The dsh ${ }^{1}$ mutation affects Fz-dependent localization}

Because the dsh ${ }^{1}$ mutation maps to the DEP domain, and the DEP domain is required for Dsh localization in response to $\mathrm{Fz}$, we hypothesized that the dsh ${ }^{1}$ mutation may disrupt membrane localization. We therefore examined the behavior of $\mathrm{dsh}^{1}$ in the Xenopus assay. Expressed alone, Dsh ${ }^{1}$-GFP associates with cytoplasmic vesicles (Fig. 4C). In the presence of Fz, Dsh1-GFP localizes to the cell cortex, but the cortical Dsh ${ }^{1}$-GFP remains vesicular, rather that distributing evenly as does the wild-type protein (Fig. 4). We propose that the dsh ${ }^{1}$ mutation all ows translocation, but impairs the ability of $\mathrm{Dsh}^{1}$ to associate with its target at the membrane, and that this altered membrane interaction diminishes the ability of $\mathrm{Dsh}^{1}$ to function in PCP signaling.

\section{DFz2 fails to induce membrane localization of Dsh}

Because DFz2 has been proposed to serve as the receptor for $\mathrm{Wg}$, we tested whether it could also induce membrane localization of Dsh. In contrast to Fz, we found that DFz2 fails to recruit Dsh-GFP to the membrane (Fig. 1H). Although we were unable to verify that wildtype DFz2 was expressed, a myc-tagged DFz2 was expressed in a pattern similar to that seen for $\mathrm{Fz}$, and it al so failed to induce Dsh-GFP membrane localization (not shown). One explanation for the failure of DFz2 to recruit Dsh is that an endogenous ligand is present and required to activate $\mathrm{Fz}$, but no endogenous ligand for DFz2 is present. To rule out this possibility, we expressed $\mathrm{Wg}$, a ligand for DFz2, together with DFz2 and

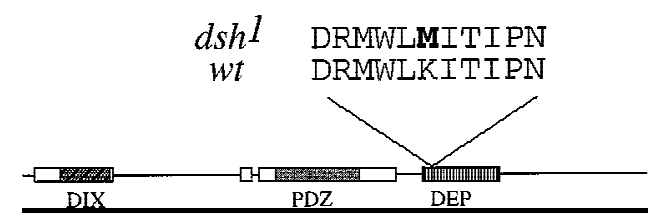

Figure 3. Sequence of the dsh ${ }^{1}$ mutant allele. The dsh ${ }^{1}$ allele carries a Lys $\rightarrow$ Met mutation in the DEP domain, at position 417. The conserved Dsh domains are boxed, and the recognized motifs are shaded.
Dsh-GFP. Wg failed to promote membrane localization of Dsh-GFP (Fig. 1I), although it was active as evidenced by its ability to induce $\mathrm{Xnr} 3$ expression and an ectopic dorsal axis as reported previously (data not shown) (Chakrabarti et al. 1992). We also verified that DFz2 was functional. Under identical conditions, DFz2 activated Xnr3 expression to levels comparable to those seen with Wg or Dsh (not shown). These data indicate that even in the presence of a functional DFz2 and a functional ligand, Dsh-GFP is not recruited to the membrane.

Dsh domains behave differently in PCP and $\mathrm{Wg}$ signaling

The dsh ${ }^{1}$ mutation is a structural mutation in the DEP domain affecting one but not the other pathway in which Dsh partici pates. Because the DEP domain is required for Fz-specific relocalization of Dsh, this suggests that the DEP domain of Dsh may be making specific contacts and functioning differently in the two pathways. To test this hypothesis more specifically, and to extend it to the other conserved D sh domains, we created a series of Dsh deletion constructs and tested them for function in the $\mathrm{Wg}$ and PCP signaling pathways.

To test function in the PCP pathway, constructs were expressed ubiquitously at $24 \mathrm{hr}$ after pupariation (AP), when PCP signaling is known to occur (Krasnow and Adler 1994). We have demonstrated that overexpression of full-length Dsh causes a dominant PCP phenotype (Fig. 5C). This phenotype, although reminiscent of the loss-of-function dsh ${ }^{1}$ phenotype, is distinct because overexpression of Dsh suppresses the $\mathrm{dsh}^{1}$ phenotype (Fig. 5H), and because a distinct and stereotypical pattern of polarity is seen (Fig. 5B,C). Similarly, deletion constructs that showed a phenotype were determined to be functional or to be dominant negative by expressing them in a dsh ${ }^{1}$ background, and in some cases, simultaneously with full-length Dsh. Examples of the data are shown in Figure 5A-H. Expression of only the DEP domain produces a polarity phenotype that is similar to $\mathrm{dsh}^{1}$, and was demonstrated to be dominant negative. Dsh( $\triangle \mathrm{bPDZ})$ and Dsh( $\triangle \mathrm{DEP}+)$ behaved similarly, whereas $D$ sh $(\Delta \mathrm{DIX})$ produced only a weak phenotype in wild type that could not be further characterized (Fig. $5 G)$.

Function was tested in the $\mathrm{Wg}$ pathway by asking whether these constructs could either rescue dsh mutant embryos or cause dominant-negative effects in phenotypically wild-type embryos. To do so, mRN As for the various constructs were created, and these were injected into embryos that were either mutant for dsh or phenotypical ly wild type. These were generated from the same cross (because the dsh maternal effect is paternally rescuable) and could be distinguished by the presence or absence of the cuticle marker shaven baby (svb). In this way, the ability to rescue the mutant phenotype, as well as the ability to function as a dominant negative in a phenotypically wild-type background, could be assessed by scoring the cuticle phenotype (Klingensmith et al. 1996). Examples of the assay results are shown in Figure 5I-N. 

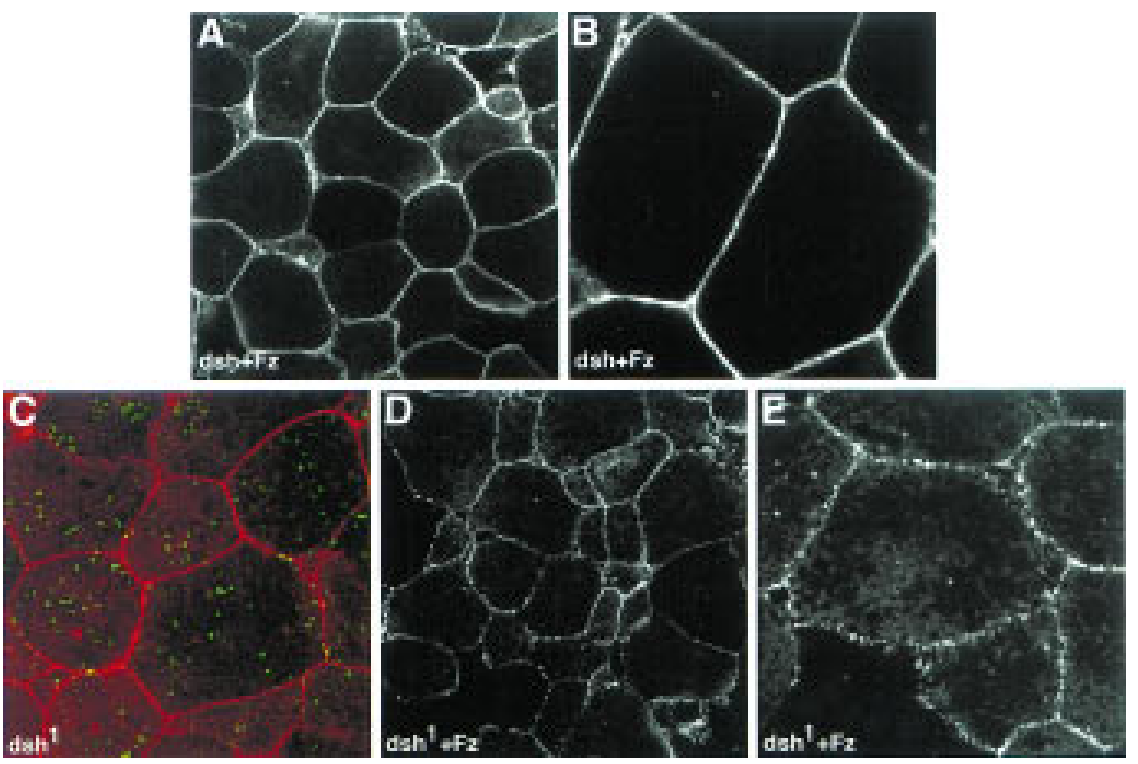

Figure 4. The dsh ${ }^{1}$ mutation affects Fzdependent localization. $(A, B)$ In response to $\mathrm{Fz}$, Dsh-GFP redistributes to the plasma membrane in a diffuse pattern. $(D, E)$ In contrast, Dsh ${ }^{1}$-GFP redistributes to the membrane but remains associated with vesicles at the cell periphery. This effect was seen at all ratios of dsh to $\mathrm{fz}$ RN As; the experiment shown used a ratio of 2:1. (C) In the absence of Fz, Dsh ${ }^{1}-G F P$ is vesicular, and is indistinguishable from wild-type Dsh-GFP.
The structures of the constructs tested, and the results of the structure/function analyses, are shown in Figure 6. A striking discordance between the activities of the various constructs in the two assays is noticeable immediately. For example, the individual domains Dsh(DIX) and Dsh(bPDZ), are each dominant negative for Wg sig-
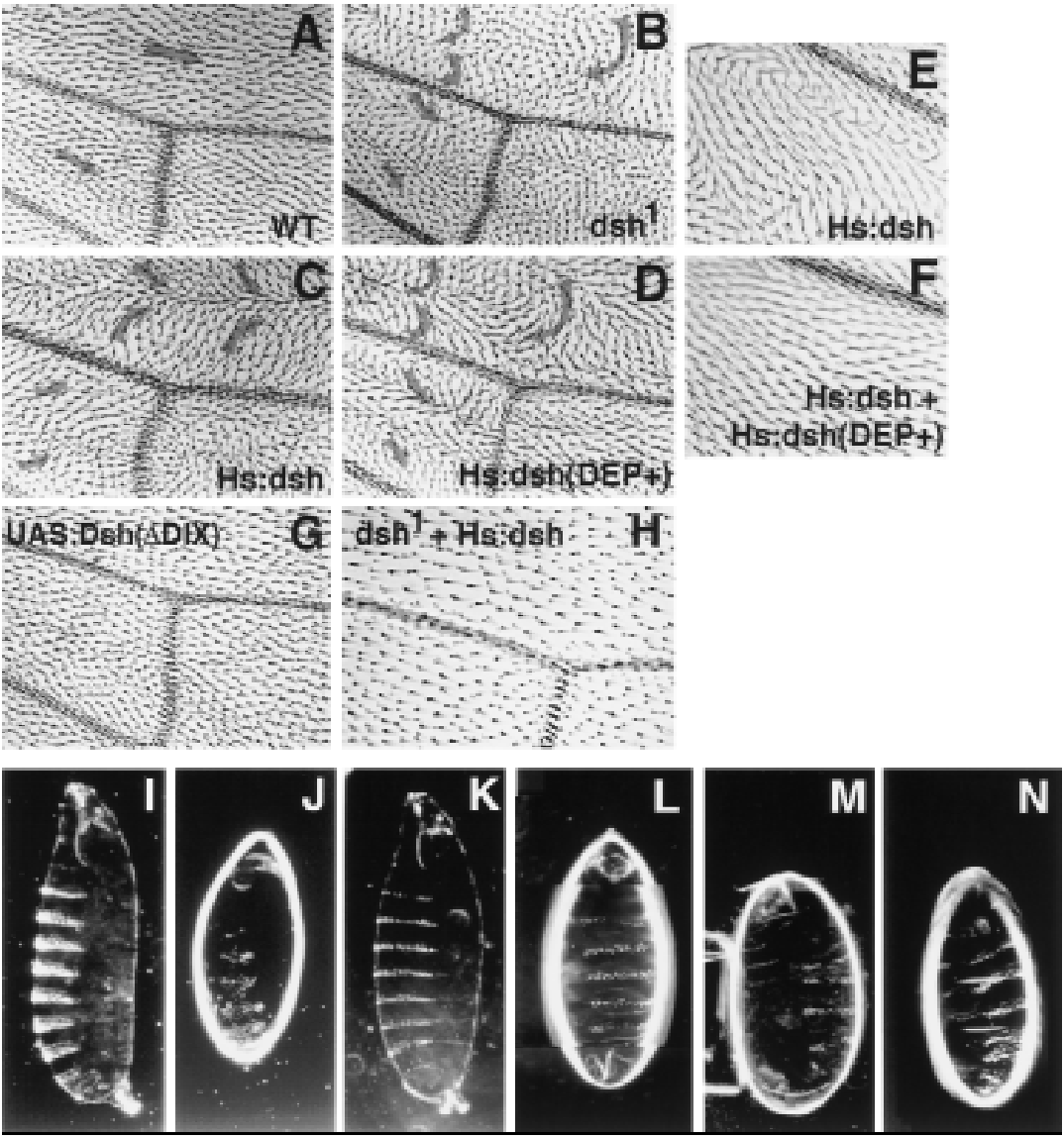

Figure 5. Dsh structure function analyses. Analysis of function in PCP signaling. Regions of wings from (A) wild type, (B) dsh ${ }^{1}$, (C) T8H s:dsh/ + heat-shocked for $1 \mathrm{hr}$ at $24 \mathrm{hr}$ AP, (D) Hs:dsh(DEP+) heat-shocked for $2.5 \mathrm{hr}$ at 24 hr AP. N ote that the Hs:dsh(DEP+) wing resembles the dsh ${ }^{1}$ wing, rather than the $\mathrm{Hs}$ :dsh wing. A different region of a T15Hs:dsh/+wing shows a pattern (E) that is suppressed by simultaneous expression of Hs:dsh(DEP+) (F). (The flies in $E$ and $F$ were heat-shocked for $1 \mathrm{hr}$ at 24 hr AP. A slightly higher magnification is shown.) Expression of Dsh(DEP+) in a dsh ${ }^{1}$ mutant failed to alter the dsh ${ }^{1}$ phenotype (not shown). By these criteria, Dsh(DEP+) behaves as a dominant negative. Expression of wildtype Dsh suppresses the dsh ${ }^{1}$ phenotype $(H$; the wing is marked with yellow; thus the hairs are finer and have less contrast. A slightly higher magnification is shown). Dsh( $\Delta \mathrm{DIX})$ produced only a weak phenotype when expressed by UAS and a range of GAL4 drivers (Hs:GAL4 is shown, G). A nalysis of function in Wg signaling. (I) A wild-type cuticle; (J) a svb, dsh cuticle. The dsh mutant cuticle shows shortening, fusion of denticle bands, and absence of the head skel eton and filzkorper characteristic of mutants in the Wg pathway. Injection of wild type mRNA into the mutant embryos results in complete rescue of segmentation, the head skeleton and the filzkörper (K). Cuticles injected with Dsh( $\triangle \mathrm{bPDZ})$ are identical. Similarly, injection of partially functional constructs partially rescues segmentation, the head skeleton and the filzkörper to varying extents; e.g., $(L) D s h(\Delta * E P+)$ and $(M) D s h(\Delta D I X)$. Conversely, injection of dominant-negative constructs causes wild-type embryos to show a segmentation phenotype and loss of the head skeleton and filzkörper similar to the mutant embryos; (N) Dsh(DIX) and Dsh(bPDZ) (not shown). 
Figure 6. Structures of the Dsh constructs. The conserved domains are as in Fig. 3, and the nonconserved basic domain is indicated (b). Results of the structure-function analyses are shown in semiquantitative form. Embryos that hatched are indicated; (DN ) dominant negative. A detailed summary is found in $M$ aterials and $M$ ethods. (GFP) Some of the same constructs were fused to GFP at their carboxyl termini and used in the animal cap assays.

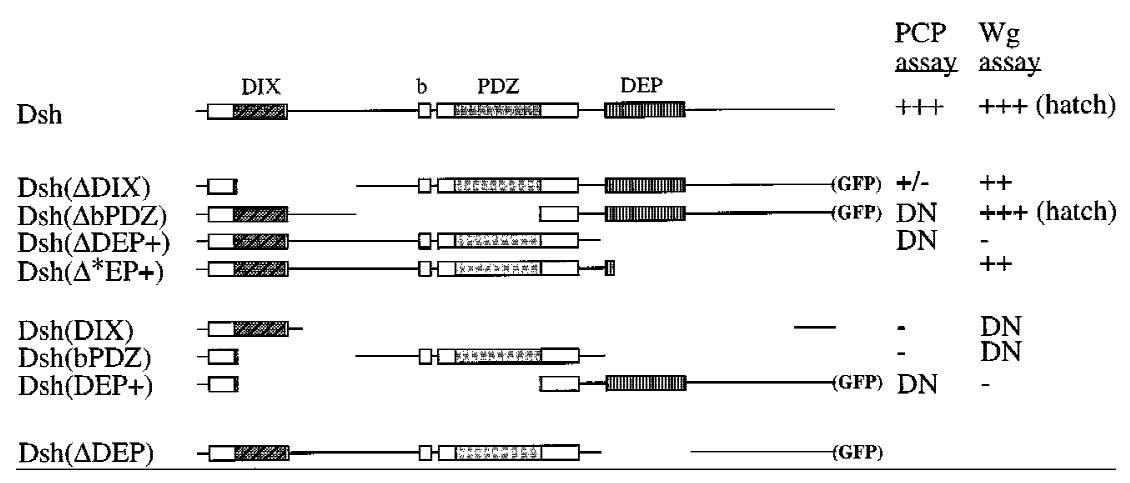

naling but have no effect on PCP signaling. The simplest explanation for these observations is that the various domains of Dsh are contacting different partners in the two pathways. The behavior of the DEP domain in the Xenopus assay is consistent with this hypothesis.

Several of these results are germane specifically to the function of Dsh in PCP signaling. Del etion of most of the DEP domain [Dsh $(\Delta * E P+)]$ leaves Wg signaling largely intact; however, in PCP signaling, a dominant-negative activity results from loss of the DEP domain [Dsh( $\triangle \mathrm{DEP}+)]$. Conversely, expression of just the DEP domain also had a dominant-negative PCP but not $\mathrm{Wg}$ phenotype [Dsh(DEP+)]. This suggests a critical role for the DEP domain in PCP signaling that is not shared by the Wg pathway.

The DIX domain anchors Dsh to cytopl asmic vesicles, and its deletion reduces function in both pathways. Anchoring may therefore be important for both pathways.

Also of note, deletion of the PDZ domain [Dsh( $\triangle \mathrm{bPDZ})]$ resulted in a construct that is functional for Wg signaling but dominant negative for PCP signaling. It must therefore play a significant role in PCP signaling, but a potential role in Wg signaling may only be significant when the protein is expressed at wild-type levels (see below).

Wg and PCP signaling pathways require different components downstream of Dsh

To determine whether Dsh plays the same or different roles in PCP and Wg signaling, we evaluated two distinct models. In the first model, Dsh has similar functions in the two pathways, and may use a common set of effectors. In such a model, Dsh, Zw3, and Arm might function as a signaling cassette in a manner analogous to the functions of Ras and Raf. In an al ternate model, Dsh has different functions in the two pathways, and interacts directly with different downstream components.

Because overexpression of either Dsh or Fz at $24 \mathrm{hr}$ AP produces dominant PCP phenotypes (Krasnow and Adler 1994; Adler et al. 1997; see below), we asked whether overexpression of Zw3 or Arm might al so affect planar polarity. Overexpression of Zw3, or an activated Arm protein (Arm ${ }^{\text {S10; }}$ Pai et al. 1997) at $24 \mathrm{hr}$ AP failed to produce any effect on PCP (Fig. 7A,B).

We then asked whether loss of function had any effect on PCP. Because clones of cells carrying null mutations in arm cannot be recovered in the adult (Peifer et al. 1991; Fig. 7C), we selected a hypomorphic arm allele, $\mathrm{arm}^{\mathrm{H} 8.6}$, that is strongly mutant for Wg signaling (Klingensmith et al. 1989). Clones mutant for $\operatorname{arm}^{\mathrm{H} 8.6}$ (and marked with $\mathrm{f}^{36 a}$ ) showed no disturbance in planar polarity (Fig. 7E), suggesting that Arm plays no role in this signaling event.

Clones mutant for zw3 alter cell fate, causing epithe lial cells in the wing to adopt a neural fate and produce tufts of bristles (Simpson et al. 1988; Fig. 7C). We therefore generated clones that were doubly mutant for zw3 and scute (sc). sc mutants are unable to adopt the neural fate such that sc zw3-mutant cells remain epithelial. $z$ w3 sc double-mutant cl ones (marked with $f^{36 a}$ ) show no polarity disturbance, suggesting that $Z$ w3 is not invol ved in PCP signaling (Fig. 7F).

Although a null arm allele cannot be used for this analysis, and an activated form of zw3 is not available, we believe these experiments argue strongly against a role for these genes in planar polarity signaling. Similarly, since mutations in the planar polarity genes $\mathrm{fz}, \mathrm{pk}$,

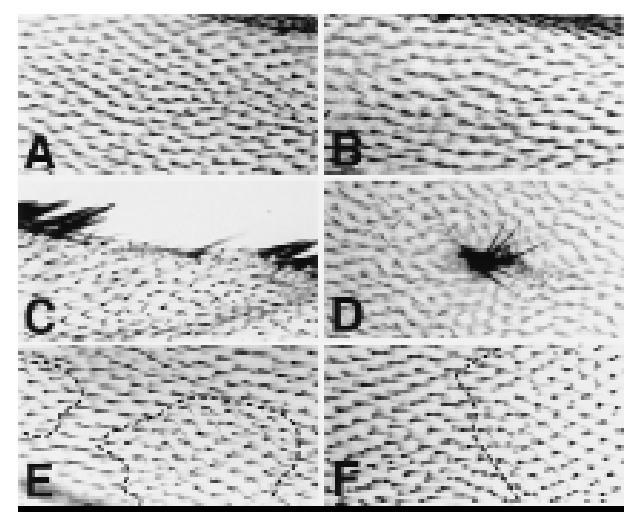

Figure 7. Arm and $Z w 3$ have no role in PCP signaling. Wings from flies in which Arm ${ }^{\mathrm{S10}}$ (A) or Zw3 (B) were overexpressed show a wild-type polarity phenotype. Clones of $\operatorname{arm}^{\mathrm{H} 8.6}$ (C) or zw3 (D) mutant cells marked with $\mathrm{f}^{36 a}$ produce wing margin nicks and tufts of bristles, respectively. The zw3 mutant cells appear to cause polarity distortions in the surrounding wildtype tissue, probably by grossly distorting the architecture of the epithelium. However, cells in arm $\mathrm{f}^{36 \mathrm{a}}$ mutant clones in the interior of the wing produce hairs of wild-type polarity $(E)$, as do cells in $\mathrm{SC}^{\mathrm{B} 57} \mathrm{zW} 3 \mathrm{f}^{36 \mathrm{a}}$-mutant clones (F). 
in, fy, and mwh produce viable adults, there is no evidence of a role for these genes in $\mathrm{Wg}$ signaling. Thus, the known components functioning downstream of Dsh in both pathways are distinct.

\section{Reciprocal titration of PCP and Wg signaling}

The above analyses suggest that Dsh has different interactions in PCP and Wg signaling. This model predicts an additional genetic behavior. If $\mathrm{Wg}$ and planar polarity signaling utilize Dsh in a common fashion, then ectopic activation of one pathway should be able to cross-activate the other by promiscuously activating Dsh. In contrast, if each pathway utilizes Dsh in a distinct fashion, then ectopic activation might sequester Dsh in pathwayspecific complexes, rendering it unavailable and therefore titrating the activity of the other pathway.

These possibilities could best be tested under conditions in which Dsh is limiting. Overexpression of $\mathrm{Fz}$ causes a dominant gain-of-function PCP phenotype (Fig. $8 \mathrm{~B})$, and this phenotype is sensitive to the dose of dsh (Krasnow and Adler 1994). To ask whether Wg can crossactivate Dsh activity for PCP signaling, or if it can sequester Dsh, we simultaneously ubiquitously expressed Wg, and asked if the Fz-overexpression phenotype was either enhanced or suppressed. Figure 8C shows that ectopic expression of Wg suppresses the Fz overexpression phenotype, suggesting that activation of Wg signaling may titrate the amount of Dsh available for PCP signaling.

We conducted the reciprocal experiment by asking if ectopic activation of the PCP pathway could interfere with Wg signaling. Because the ligand for PCP signaling is unknown, we overexpressed Fz during embryogenesis,

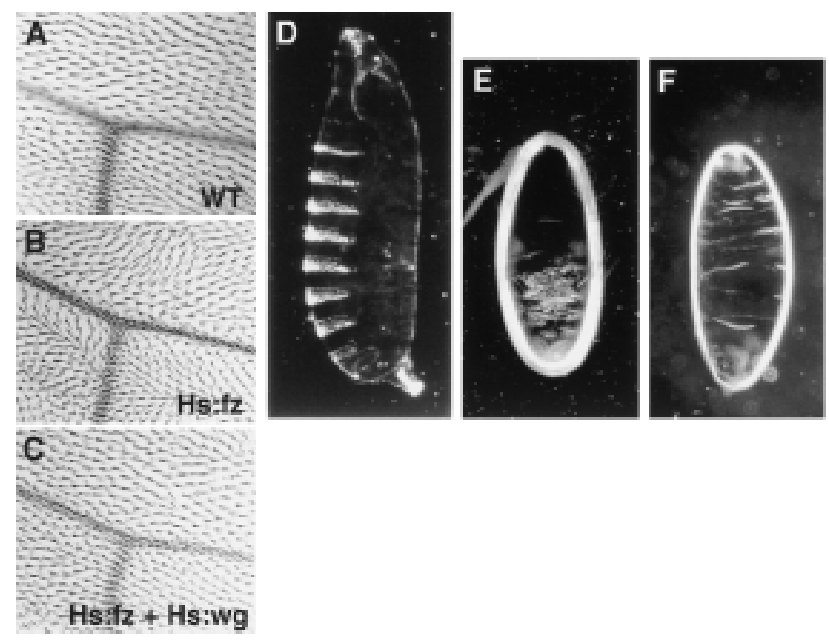

Figure 8. Reciprocal titration of the PCP and $\mathrm{Wg}$ pathways. Wings from wild-type (A), $\mathrm{Hs}: \mathrm{Fz} /+(B)$, and $\mathrm{Hs:Fz/+;} \mathrm{Hs:wg/+}$ (C), each heat-shocked for $1.5 \mathrm{hr}$ at $24 \mathrm{hr}$ AP. Overexpression of $\mathrm{Hs}$ :wg al one at this time has no phenotype (not shown). However, it suppresses the Hs:fz overexpression phenotype. Shown are embryos that are wild type (D), U 32A/U 32A; U ASfz/ + (E), and U 32A/U 32A; U ASdsh43-1-B-1/ + (F). Whereas overexpression of Dsh produces naked cuticle $(F)$, overexpression of $F z$ leads to lawns of denticles (E). and analyzed the cuticle phenotype. Embryos developed with lawns of denticles and were reminiscent of wg-mutant embryos, or those expressing dominant-negative Dsh constructs (Fig. 8E, al though note that under heat shock control, Fz expression produces a very weak phenotype reminiscent of $\mathrm{Wg}$ overexpression; Tomlinson et al. 1997). Our result suggests that titration can occur in this direction as well. We cannot rule out the possibility that the titration we observed in these experiments results from a promiscuous interaction between $\mathrm{Wg}$ and $\mathrm{Fz}$ (Bhanot et al. 1996), although this interaction may not occur in vivo (Cadigan et al. 1998). Our observations are equally consistent with the possibility that under these conditions, activity of one pathway titrates the Dsh level available for the other.

\section{Discussion}

The role of Dsh in PCP signaling

Through the PCP signal, cells determine their orientation in the plane of the epithelium, and reorganize their cytoskel etons in a polarized array. Although theligand(s) mediating PCP signaling is not known, the signal must somehow be detected asymmetrically and the response generated asymmetrically by each cell. Recent work suggests that asymmetric distribution or activation of $\mathrm{Fz}$ may produce this signal (Adler et al . 1997). Here, we have shown that relocalization of Dsh to the membrane is required for $\mathrm{PCP}$ signaling. We speculate that in vivo, asymmetry in PCP signal ing results from an asymmetric relocalization of Dsh to the membrane. Dsh could then serve as a marker establishing intrinsic polarity and directing the location of prehair initiation (Wong and Adler 1993). This could occur through polarized cytoskeletal remodelling in a fashion similar, for example, to the mechanism by which Saccharomyces cerevisiae orient and grow buds (Chant 1996). A similar mechanism, using Fz and Dsh, may function to orient ommatidia in the developing Drosophila eye (Gubb 1993; Strutt et al. 1997; Tomlinson et al. 1997), and may also require activation of the JNK pathway (Strutt et al. 1997; Boutros et al. 1998).

Whereas it is unclear how Dsh is recruited to the membrane, imperfect colocalization suggests that the mechanism does not depend on direct binding of Fz and Dsh. Two mechanisms can be envisioned for its recruitment. First, a signal from Fz may result in a post-translational modification of Dsh, and this modification could then al low it to interact with a target at the membrane. Second, Fz signaling might modify the docking site, which in turn recruits Dsh.

The data presented here do not address directly whether Fz-dependent localization of Dsh to the membrane is signal dependent. Although no exogenous ligand was expressed, it is possible that overexpression of $\mathrm{Fz}$ was sufficient to mimic the ligand-bound state. Alternatively, an endogenous ligand might be present that is capable of recognizing and activating Fz. In support of this possibility, a Fz construct lacking the ligand-binding 
domain ( $F z \Delta N)$ was incapable of inducing membrane localization of Dsh-GFP (not shown).

\section{Functions of Dsh domains in PCP signaling}

The functions of Dsh that allow it to participate in discrete signaling mechanisms are not known. The results presented here allow us to draw some inferences concerning the functions of the conserved domains in both pathways, although a more complete understanding awaits identification of the proteins with which these domains interact. In the Fz-mediated pathway, the PDZ domain is not required for translocation to the membrane. However, a protein lacking this domain is dominant negative for PCP signal ing, suggesting that the PDZ domain plays a role in PCP signaling, perhaps recruiting another component of the pathway. An interaction with the DIX domain appears to anchor Dsh to cytoplasmic vesicles, but the DIX domain might also participate in an interaction at the membrane.

The DEP domain is both necessary and sufficient for an interaction that brings Dsh to the membrane and fiIopodia. Expressing just the DEP domain inhibits the function of endogenous Dsh in planar polarity signaling, presumably by blocking this interaction, further suggesting a physiologic importance of this localization. Deletion of the DEP domain produces a dominant-negative protein, indicating that mislocalized Dsh can interfere with PCP signaling, perhaps by nonproductive interaction with another component of the pathway. These results suggest that localization of Dsh is important for PCP signaling, since Dsh molecules that cannot localize properly, or those that block localization of the endogenous Dsh behave as dominant negatives. It will be important to determine the binding partners for the Dsh domains to understand this process in more detail.

DEP domains have been recognized in a group of proteins related by their ability to regulate GTPases: regulator of G-protein signaling (RGS), guanine nucleotide dissociation stimulator (GDS), and GTPase-activating protein (GAP) proteins (Ponting and Bork 1996). Although present in many members of these groups, other domains are responsible for di rectly interacting with and regulating the GTPases. DEP domains are therefore likely involved in a different level of regulation. Our data indicate that the Dsh DEP domain is important for localization of Dsh during PCP signaling. egl 10, an RGS protein in Caenorhabditis elegans, also displays a restricted subcellular local ization that depends on its DEP domain (Koelle and Horvitz 1996). DEP domains may therefore serve to localize proteins to specific compartments in the cell.

The involvement of other DEP domain proteins in regulation of GTPases l eads us to consi der the possibility that Dsh also plays such a role. As noted previously, the small GTPases RhoA and Racl appear to be important for PCP signaling (Eaton et al. 1995, 1996; Strutt et al. 1997a). It is al so possible that heterotrimeric $G$ proteins play a role. PCP signaling may work by a mechanism homologous to the Wnt5a signaling pathway in
Xenopus, in which a G-protein mechanism has been implicated (Slusarski et al. 1997a). It may also be homologous to a Wnt mediated polarity signal in C. elegans embryos (Rocheleau et al. 1997; Thorpe et al. 1997), which also requires a G protein (Zwaal et al. 1996). It will be important to determine what interactions might exist between Dsh and GTPases in PCP signaling.

\section{Functions of Dsh domains in Wg signaling}

It is more difficult to make specific inferences regarding the functions of these domains in Wg signal ing. The DEP domain is not essential for Wg signaling, as $\mathrm{Dsh}\left(\Delta^{*} \mathrm{EP}+\right)$ retains function. We note that the PDZ domain is dispensable for Wg signaling when Dsh is expressed at high levels, as was done in the embryo-injection rescue assay, but may have an important function when the protein is expressed at wild-type levels (Y anagawa et al. 1995; see below). One possibility is that the PDZ is used to localize Dsh but that overexpression allows sufficient levels of $\mathrm{Dsh}(\triangle \mathrm{bPDZ})$ to reach the appropriate location. Overexpression of the PDZ domain could therefore interfere with this localization, resulting in dominant interfering activity.

In a cell-culture assay for Wg signaling, Dsh induced accumulation of A rm; however, a Dsh construct lacking the PDZ domain failed to do so (Yanagawa et al. 1995). In addition, a Xenopus Dsh lacking the PDZ functioned as a dominant negative (Sokol et al. 1996). Although we cannot explain fully the apparent discrepancy between these results and ours, in both these experiments, the truncated proteins were expressed in a wild-type background, whereas in the experiment we have presented, rescue was assessed in a dsh null mutant background. When Dsh( $\triangle \mathrm{bPDZ})$ mRNA was injected into wild-type embryos, we observed a modest degree of denticle fusions that might be interpreted as dominant-negative activity (data not shown). We conclude that Dsh( $\triangle b P D Z)$ can rescue null mutants, but may function as a weak dominant negative in the presence of wild-type Dsh.

\section{Differential activation of Dsh}

We have presented five lines of evidence indicating that Dsh transduces two distinct signals, the Wg and PCP signals, as a result of its differential activation by the two pathways: (1) Dsh is recruited differentially to the membrane by the putative receptors for the two pathways; (2) the dsh ${ }^{1}$ allele selectively affects PCP signaling, and encodes a structural alteration in a domain required for translocation to the membrane; (3) domains in Dsh are active differentially in PCP and Wg signaling; (4) downstream components of the two pathways are not shared; and (5) Dsh function in one pathway can be titrated by activation of the other pathway.

In Xenopus animal caps, Dsh is recruited to the membrane or cell cortex in response to Fz, and is al so induced to associate with filopodia. We propose that a similar localization is likely to occur during PCP signaling, although it may be only a fraction of the Dsh that localizes in vivo, and the relocalization may be restricted in a 
signal-dependent fashion to a small portion of the cell (see bel ow). The small size of the cells would make this very difficult to detect.

In contrast, DFz2, the putative $\mathrm{Wg}$ receptor, appears not to induce relocalization of Dsh, regardless of the presence of ligand. One of two possible conclusions may be drawn from these obervations. The results might indicate that Dsh is activated differently by the PCP and Wg pathways; this conclusion would be consistent with the other data presented here. In support of this model, Xenopus Wnt8 (XWnt8), which, like Wg, induces axis duplication by activating the Wnt pathway, fails to induce membrane localization of Xenopus Dsh (YangSnyder et al. 1996). Therefore, functional activation of the Wnt (Wg) pathway by either Wg or XWnt8, fails to Iocalize Dsh to the membrane.

An alternative explanation for the failure of $D F z 2$ to recruit $D$ sh to the membrane is that multiple receptors are required to transduce a complete response to $\mathrm{Wg}$, or that DFz2 does not function as the Wg receptor in vivo, despite its ability to transduce the Wg signal in cultured cells (Bhanot et al. 1996). Consistent with the former possibility, it has been argued that distinct domains in Wg activate different subsets of the Wg response (Bejsovec and Wieschaus 1995; Hays et al. 1997). The receptor $\mathrm{N}$ otch has also been proposed to function as a Wg receptor (Couso and M artinez-Arias 1994). We found that $\mathrm{N}$ otch also failed to recruit $\mathrm{D}$ sh to the membrane in the Xenopus animal cap assay (not shown); we found previously that colocalization in S2 cells required capping by DI-expressing cells (Axelrod et al. 1996). Additional analyses of N otch, DFz2, and other candidate receptors, will be required to asses their possible roles in Wg signaling.

We cannot rule out the possibility that in Drosophila, some polarity information is transduced al ong with cell fate information by Wg signaling (Thiesen et al. 1994; Tomlinson et al. 1997), or that Fz is required for mediation of Wg signaling in addition to its role in PCP signaling (Bhanot et al. 1996). In other words, the specificity of these pathways may be partial rather than absolute. In this context, it is interesting to note that in cultured Drosophila cells, a small fraction of Dsh was found in the membrane fraction of $\mathrm{Wg}$ treated cells ( $Y$ anagawa et al. 1995).

\section{Divergence of Wnt pathways in other organisms}

Evidence for a divergence of Fz-mediated signaling pathways can al so be found in other organisms. In C. elegans, genes encoding members of a Wnt signaling pathway are required for a descendent of the EMS blastomere to adopt the $E$ fate (Rochel eau et al. 1997; Thorpe et al. 1997). In addition, the rotation of a number of mitotic spindles, including that of the EMS cell, produces a polarized cell division, and depends on Wnt activity [and on G-protein function (Zwaal et al. 1996)]. Induction of the E cell fate was found to require the homologs of Wnt, Fz, Arm, and Pan, but only the Wnt and Fz homologs were required for polarization of the EMS and other cells. These results suggest that there is a divergence in the signaling pathway downstream of Fz but upstream of Arm.

Additional evidence of distinct functions for Dsh comes from observations in mice and chicks. Although little data concerning their function exists, it has been observed that in PC 12 cells, two of the three murine Dsh homologs, $\mathrm{Dvl}-1$ and $\mathrm{Dvl}-2$, respond to Wnt-1 by adopting different subcellular local izations: Dvl-1 local izes to the membrane, whereas Dvl-2 local izes to the cytoskeleton (Steitz et al. 1996). It is tempting to speculate that each of these Dsh homologs is involved differentially in transducing polarity and cell fate or other distinct signals. Similarly, in the chick limb bud, Wnt3a and Wnt7a induce distinct responses in the mesoderm that are $\beta$ catenin dependent and independent, respectively (Kengaku et al. 1998).

Studies of Wnt signaling in Xenopus provide evidence of divergent pathways as well. Xenopus Wnt1 (XWnt1) induces axis duplication by activating a pathway similar to that used by Wg. In contrast, Xenopus Wnt5a (XWnt5a) fails to induce axis duplication, but rather alters morphogenetic movements during gastrulation (Moon et al. 1993), perhaps by activating a G-protein coupled pathway resulting in decreased cell adhesion and increased intracellular $\mathrm{Ca}^{2+}$ levels (Slusarski et al. 1997a,b). A difference in the ability of rFzl and rFz2 to activate these pathways has also been observed (YangSnyder et al. 1996; Sl usarski et al. 1997a; J.D. Brown and R.T. Moon, unpubl.). Of note, XWnt5a blocks the axisduplicating activity of XWnt1, but not that of downstream components of the XWntl pathway, $\beta$-catenin or kinase dead-Gsk-3 (Torres et al. 1996). This is reminiscent of the ability of Wg to block signal transduction in the PCP pathway and vice versa, and might occur through a similar mechanism of titrating Dsh. In contrast, a heterologous Fz, human Fz5 (hFz5), can serve as an "adaptor", allowing XWnt5a to induce axis duplication (He et al. 1997). hFz5 appears to bind XWnt5a, but has the specificity to activate the Wg-like axis duplicating pathway. Therefore, Fz pathways in Xenopus have differing specificities, and may functionally titrate each other. The specificity with which the pathways are activated appears to be a function of the Fz protein(s) recognized by each Wnt.

\section{Conclusions}

Few well understood examples of how extracellular signals regul ate the cytoskel eton exist. Dsh links the activity of the Fz family of receptors to control of the cytoskel eton, and we propose that it does so by a mechanism distinct from its function in $\mathrm{Wg}$ signal transduction. Since it lacks recognizable sequences suggesting an enzymatic activity, Dsh may serve as a scaffolding or adapter protein. PDZ domains are found in such proteins, but the functions of DEP and DIX domains are yet to be defined. Elucidation of Dsh function in PCP and Wg signaling may shed light on the functions of these motifs, as well as enlighten our understanding of how 
Dsh may contribute to the specificity of Fz-mediated signaling.

\section{Materials and methods}

Overexpression and generation of mutant clones

zw3, arm, and arm ${ }^{\text {s10 }}$ (Pai et al. 1997), wg (N oordermeer et al. 1992), fz (Krasnow and Adler 1994; Adler et al. 1997), fz $\Delta \mathrm{N}$, dsh [two insertions were used: T 8 (A xel rod et al. 1996), and T 15 (on the third chromosome)], and the dsh del etion constructs were overexpressed using either the heat shock promoter in pCaSpeR-hs (Thummel et al. 1988; Thummel and Pirotta 1992), or by using pUAST (Brand and Perrimon 1993) crossed with hs-GAL4 (Brand et al. 1994) or the maternally expressed U 32A:GA L4 (mat $\alpha-G A L 4-V P 16$, containing amino acids 1-144 of GAL4 fused to the transcriptional activator domain of VP16, and expressed from the $\alpha 4$-tubulin promoter, was a gift of D. St Johnston, Wellcome/CRC Institute, Cambridge, UK). Transformants were obtained as described (Spradl ing 1986; Robertson et al. 1988). Heat shocks at $37^{\circ} \mathrm{C}$ were applied for the indicated times and durations. Where appropriate, overexpression was done in dsh $1 / Y$ males, or in the presence of UAS:dsh or Hs:dsh.

Clones of homozygous zw3 or arm-mutant cells were generated using the FLP technique (Chou and Perrimon 1992). Somatic clones were produced by crossing FM7/y arm ${ }^{H 8.6} \mathrm{f}^{36 a}$ $\mathrm{FRT}^{9-2}$ or FM7/Df(1) SC ${ }^{\mathrm{B} 57}$ sgg $^{\mathrm{D} 127} \mathrm{f}^{36 a} \mathrm{FRT}^{19 \mathrm{~A}}$ females to ovo ${ }^{\mathrm{D} 2}$ $\mathrm{FRT}^{9-2} ; \mathrm{FLP}^{38} / \mathrm{FLP}^{38}$ or $\mathrm{FRT}^{19 \mathrm{~A}} / \mathrm{Y} ; \mathrm{MKRS} \mathrm{FLP}^{\mathrm{M} 42} /+$ males, and heat-shocking at $37^{\circ} \mathrm{C}$ for $2 \mathrm{hr}$ during third instar. FRT ${ }^{9-2}$, FLP ${ }^{38}$, MKRS, FLPM ${ }^{42}$, and FRT ${ }^{19 A}$ are as described by Chou and Perrimon (1992), Siegfried et al. (1994), and Xu and Rubin (1993), respectively. The ovo ${ }^{\mathrm{D} 2}$ mutation produces dominant female sterility and has no effect on development of somatic tissues. Flies bearing $\mathrm{arm}^{\mathrm{H} 8.6} \mathrm{Clones}$ were raised at $29^{\circ} \mathrm{C}$ because of the temperature sensitivity of the allele (Klingensmith et al. 1989).

All wings were mounted in Euparal (Asco Laboratories, $M$ anchester, UK) for examination and photography.

\section{$\mathrm{dsh}^{1}$ cloning and sequencing}

Total genomic DNA from dsh ${ }^{1}$ males was isolated, cut with Sall and Xbal, size fractionated, and cloned into pBSK (Stratagene). Clones were screened by hybridization with dsh CDNA. Positives were sequenced. The $d s h^{1}$ mutation was recreated in a wild-type dsh genomic fragment, cloned into pCaSpeR (Thummel et al. 1988), and transformants generated (Spradling 1986; Robertson et al. 1988). Flies carrying the introduced gene, in up to three copies, in a dsh ${ }^{\text {v26 }}$ null mutant background were viable, and had the dsh ${ }^{1}$ phenotype.

Xenopus animal cap explants and confocal microscopy

Capped RN As encoding each cDN A construct were synthesized with the mM essage Machine kit (Ambion, Austin, TX) from linearized DNA templates. The indicated RN As (250-500 pg) were injected into the animal pole of two blastomeres at the four-cell stage and injected embryos were cultured to stage 9. A nimal caps dissected from injected embryos were fixed in $4 \%$ paraformal dehyde, $10 \mathrm{~mm}$ HEPES (pH 7.6), $100 \mathrm{~mm} \mathrm{KCl}, 3 \mathrm{~mm}$ $\mathrm{MgCl}_{2}, 2 \mathrm{~mm}$ EGTA, and $150 \mathrm{~mm}$ sucrose for $1-2 \mathrm{hr}$ at room temperature. For colocalization experiments, fixed animal caps were dehydrated in $\mathrm{MeOH}$ after which they were immunostained in PBST $+10 \%$ goat serum with either anti-DFz1 antibodies (1:1000 dilution; Park et al. 1994) or anti-human c-myc 9E10 monoclonal antibodies (1:25 dilution). Cy3-conjugated secondary antibodies (1:250 dilution; Jackson ImmunoResearch, West Grove, PA) were used to detect the localization of ectopic Fzs. The distribution of F-actin in animal cap cells was visualized with Texas Red-conjugated phalloidin (Molecular Probes, Eugene, OR). A nimal caps were mounted in Vectashield for microscopy (Vector Laboratories, Burlingame, CA).

The local ization of ectopic GFP-tagged Dsh and Fz proteins in Xenopus animal cap cells was determined by laser scanning confocal microscopy. Confocal microscopy was performed using a Bio-Rad M RC600 scan head (Bio-Rad Labs, Hercules, CA) and a Nikon Optiphot-2 microscope (N ikon, Melville, NY). All images were collected with a $60 \times 1.4 \mathrm{NA}$ PlanApo objective. Multilabeled samples were scanned sequentially using appropriate filter blocks to ensure that there was no bleedthrough of fluorescence between channels. Digital images were processed using Adobe Photoshop software (San Jose, CA).

\section{RNA injection rescue assay}

Capped RN As for Dsh and the deletion constructs were synthesized in vitro and injected into svb dsh germ-line clone embryos or their paternally rescued siblings, and cuticles prepared and examined as described previously (Klingensmith et al. 1996).

\section{Expression constructs}

Dsh deletion constructs span the following coordinates (expressed as amino acid position, according to Klingensmith et al . 1994): Dsh (1-623); Dsh( $\Delta \mathrm{DIX})(1-41+152-623) ; \mathrm{Dsh}(\Delta \mathrm{bPDZ})$

Table 1. Behavior of Dsh deletion constructs in the structure/function assays

\begin{tabular}{|c|c|c|c|c|c|c|c|}
\hline \multirow[b]{2}{*}{ Construct } & \multicolumn{4}{|c|}{ PCP assay } & \multicolumn{3}{|c|}{ Wg assay } \\
\hline & in wild type & in dsh ${ }^{1}$ & in Hs:dsh & summary & in wild type & in dsh ${ }^{\vee 26}$ & summary \\
\hline Dsh & $+1^{a}$ & H+ (rescue) & & $+11^{b}$ & $H_{-c}^{c}$ & +H(hatch) & $+11^{\mathrm{b}}$ \\
\hline $\mathrm{Dsh}(\Delta \mathrm{DIX})$ & $H-$ & & & $?$ & - & + & + \\
\hline $\mathrm{Dsh}(\triangle \mathrm{bPDZ})$ & ++ & - & & DN & $H-D N^{d}$ & ++ (hatch) & $+H(+1-D N)$ \\
\hline Dsh( $\Delta \mathrm{DEP}+)$ & + & - & & DN & - & - & - \\
\hline $\mathrm{Dsh}(\Delta * \mathrm{EP}+)$ & & & & & - & + & + \\
\hline Dsh(DIX) & - & & & - & DN & - & DN \\
\hline Dsh(bPDZ) & - & & & - & DN & - & DN \\
\hline Dsh(DEP+) & + & - & rescue & DN & - & - & - \\
\hline
\end{tabular}

aDominant overexpression phenotype.

${ }^{\mathrm{b}}$ Functional.

'Slight naked phenotype consistent with Dsh or Wg overexpression.

dSlight DN phenotype. 
(1-151 +334-623); $\mathrm{Dsh}(\Delta \mathrm{DEP}+)$ (1-394); $\mathrm{Dsh}\left(\Delta^{*} \mathrm{EP}+\right)(1-423) ;$ Dsh(DIX) (1-101 + 582-623); Dsh(bPDZ) (1-41 + 152-394); Dsh(DEP+) (1-41 + 334-623); $\quad$ Dsh( $\triangle D E P) \quad(1-394+481-623)$. GFP(F64L,S65T) fusions were made after aa 621. Fz $\Delta \mathrm{N}$ had amino acid 29-242 deleted. Fz lacking the carboxyl terminus had the last six amino acids deleted and substituted with PSRASRTIVSRIT. Details of these constructions are available on request. Myc-DFz2 had six copies of the myc 9E10 epitope inserted in the Apal site in the extracellular domain. The behavior of these constructs in the structure/function assays are shown in Table 1.

\section{Acknowledgments}

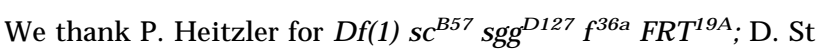
Johnston for U 32A; E. Siegfried for Hs:zw3; L.-M. Pai for UAS:arm ${ }^{\mathrm{S10}}$; and P. Adler for UAS:Fz, Hs:Fz, and Fz antisera. Thanks to P. Adler, M. Boutros, M. Mlodzik, X. He, U. Rothbächer, E. Rulifson, and R. N usse for discussions of data before publication. N.P. and R.T.M. are investigators and J.R.M. is an associate of the Howard Hughes Medical Institute. J.D.A. was supported in part by grant HD01036-02 from the $\mathrm{N}$ ational Institutes of Health.

The publication costs of this article were defrayed in part by payment of page charges. This article must therefore be hereby marked "advertisement" in accordance with 18 USC section 1734 solely to indicate this fact.

\section{References}

Adler, P.N. 1992. The genetic control of tissue polarity in Drosophila. BioEssays 14: 735-741.

Adler, P.N., C. Vinson, W.J. Park, S. Conover, and L. Klein. 1990. Molecular structure of frizzled, a Drosophila tissue polarity gene. Genetics 126: 401-416.

Adler, P.N., R.E. Krasnow, and J. Liu. 1997. Tissue polarity points from cells that have higher Frizzled levels towards cells that have lower Frizzled levels. Curr. Biol. 7: 940-949.

Axel rod, J.D., K. M atsuno, S. Artavanis-T sakonas, and N. Perrimon. 1996. Dishevelled mediates interaction between Wingless and N otch signaling pathways. Science 271: 18261832.

Bejsovec, A. and E. Wieschaus. 1995. Signaling activities of the Drosophila gene wingless are separably mutable and appear to be transduced at the cell surface. Genetics 139: 309-320.

Bhanot, P., M. Brink, C. Harryman Samos, J.-C. Hsieh, Y. Wang J.P. Macke, D. Andrew, J. N athans, and R. N usse. 1996. A new member of the frizzled family from Drosophila functions as a Wingless receptor. Nature 382: 225-230.

Boutros, M., N.P. Paricio, D.I. Strutt, and M. Mlodzik. 1998. Dishevelled activates Jun-N -terminal kinases (JNK) and discriminates between JNK pathways in planar polarity and wingless signaling. Cell 94: 109-118.

Brand, A. and N. Perrimon. 1993. Targeted gene expression as a means of altering cell fates and generating dominant phenotypes. Development 118: 401-415.

Brand, A.H., A.S. Manoukian, and N. Perrimon. 1994. Ectopic expression in Drosophila. Meth. Cell Biol. 44: 635-654.

Cadigan, K.M. and R. N usse. 1997. Wnt signaling: A common theme in animal development. Genes \& Dev. 11: 3286-3305.

Cadigan, K.M., M.P. Fish, E.J. Rulifson, and R. Nusse. 1998. Wingless repression of Drosophila frizzled 2 expression shapes the Wingless morphogen gradient. Cell 93: 767-777.

Chakrabarti, A., A. Matthews, A. Colman, and L. Dale. 1992.
Secretory and inductive properties of Drosophila wingless protein in Xenopus oocytes and embryos. Development 115: 355-369.

Chant, J. 1996. Generation of cell polarity in yeast. Curr. O pin. Cell Biol. 8: 557-565.

Chou, T.B. and N. Perrimon. 1992. Use of a yeast site-specific recombinase to produce female germline chimeras in Drosophila. Genetics 131: 643-653.

Collier, S. and D. Gubb. 1997. Drosophila tissue polarity requires the cell-autonomous activity of the fuzzy gene, which encodes a novel transmembrane protein. Development 124: 4029-4037.

Couso, J.P. and A. Martinez-Arias. 1994. Notch is required for wingless signalling in the epidermis of Drosophila. Cell 79: 259-272.

Eaton, S. 1997. Planar polarization of Drosophila and vertebrate epithelia. Curr. Opin. Cell Biol. 9: 860-866.

Eaton, S., P. Auvinen, L. Luo, Y.N. Jan, and K. Simons. 1995. CDC42 and Rac1 control different actin-dependent processes in the Drosophila wing disc epithelium. J. Cell Biol. 131: 151-164.

Eaton, S., R. Wepf, and K. Simons. 1996. Roles for Rac1 and Cdc42 in planar polarization and hair outgrowth in the wing of Drosophila. J. Cell Biol. 135: 1277-1289.

Gubb, D. 1993. Genes controlling cellular polarity in Drosophila. Development (Suppl.): 269-277.

Hays, R., G.B. Gibori, and A. Bejsovec. 1997. Wingless signaling generates pattern through two distinct mechanisms. Development 124: 3727-3736.

He, X., J.P. Saint-Jeannet, Y. Wang, J. N athans, I. Dawid, and H. Varmus. 1997. A member of the Frizzled protein family mediating axis induction by Wnt-5A. Science 275: 1652-1654.

Kengaku, M., J. Capdevila, C. Rodriguez-Esteban, J. De La Peña, R.L. Johnson, J.C.I. Bel monte, and C.J. Tabin. 1998. Distinct WNT pathways regulating AER formation and dorsoventral polarity in the chick limb bud. Science 280: 1274-1277.

Klingensmith, J., E. N oll, and N. Perrimon. 1989. The segment polarity phenotype of Drosophila involves differential tendencies toward transformation and cell death. Dev. Biol. 134: 130-145.

Klingensmith, J., R. N usse, and N. Perrimon. 1994. The Drosophila segment polarity gene dishevelled encodes a novel protein required for response to the wingl ess signal. Genes \& Dev. 8: 118-130.

Klingensmith, J., Y. Y ang, J. A xelrod, N. Perrimon, D. Beier, and D. Sussman. 1996. M ouse dvl-2 encodes a functional homolog of the Drosophila dishevelled gene. Mech. Dev. 58: 1526.

Koelle, M.R. and H.R. Horvitz. 1996. EGL-10 regulates G protein signaling in the $C$. el egans nervous system and shares a conserved domain with many mammalian proteins. Cell 84: $115-125$.

Krasnow, R.E. and P.N. Adler. 1994. A single frizzled protein has a dual function in tissue polarity. Development 120: 1883-1893.

Krasnow, R.E., L.L. Wong, and P.N. Adler. 1995. Dishevelled is a component of the frizzled signaling pathway in Drosophila. Development 121: 4095-4102.

Miller, J.R. and R.T. Moon. 1996. Signal transduction through $\beta$-catenin and specification of cell fate during embryogenesis. Genes \& Dev. 10: 2527-2539.

Moon, R.T., R.M. Campbell, J.L. Christian, L.L. McGrew, J. Shih, and S. Fraser. 1993. Xwnt-5A: A maternal Wnt that affects morphogenetic movements after overexpression in embryos of Xenopus laevis. Development 119: 97-111.

Moon, R.T., J.D. Brown, and M. Torres. 1997. WNTs modulate 
cell fate and behavior during vertebrate development. Trends Genet. 13: 157-162.

M orais Cabral, J.H., C. Petosa, M.J. Sutcliffe, S. Raza, O. Byron, F. Poy, S.M. Marfatia, A.H. Chishti, and R.C. Liddington. 1996. Crystal structure of a PDZ domain. Nature 382: 649652.

N oordermeer, J., P. Johnston, F. Rijsewijk, R. Nusse, and P.A. Lawrence. 1992. The consequences of ubiquitous expression of the wingless gene in the Drosophila embryo. Development 116: 711-719.

Orsulic, S. and M. Peifer. 1996. Cell-cell signaling: Wingless lands at last. Curr. Biol. 6: 1363-1367.

Pai, L.M., S. Orsulic, A. Bejsovec, and M. Peifer. 1997. N egative regulation of Armadillo, a Wingless effector in Drosophila. Devel opment 124: 2255-2266.

Park, W.-J., J. Liu, and P.N. Adler. 1994. The frizzled gene of Drosophila encodes a membrane protein with an odd number of transmembrane domains. Mech. Dev. 45: 127-137.

Park, W.J., J. Liu, E. Sharp, and P.N . Adler. 1996. The Drosophila tissue polarity gene inturned acts cell autonomously and encodes a novel protein. Development 122: 961-969.

Peifer, M., C. Rauskolb, M. Williams, B. Riggleman, and E. Wieschaus. 1991. The segment polarity gene armadillo interacts with the wingless signaling pathway in both embryonic and adult pattern formation. Development 111: 1029-1043.

Perrimon, N. and A.P. Mahowald. 1987. Multiple functions of segment polarity genes in Drosophila. Dev. Biol. 119: 587600.

Ponting, C.P. and P. Bork. 1996. Plekstrin's repeat performance: A novel domain in G-protein signaling? Trends Biochem. Sci. 21: 245-246.

Ponting, C.P., C. Phillips, K.E. Davies, and D.J. Blake. 1997. PDZ domains: Targeting signaling molecules to sub-membranous sites. BioEssays 19: 469-479.

Robertson, H.M., C.R. Preston, R.W. Phillis, D. JohnsonSchlitz, W.K. Benz, and W.R. Engels. 1988. A stable source of P-element transposase in Drosophila melanogaster. Genetics 118: 461-470.

Rocheleau, C.E., W.D. Downs, R. Lin, C. Wittman, Y. Bei, Y.-H. Cha, M. Ali, J.R. Preiss, and C.C. M ello. 1997. Wnt signaling and an APC-related gene specify endoderm in early $C$. elegans embryos. Cell 90: 707-716.

Semenov, M.V. and M. Snyder. 1997. Human Dishevelled genes constitute a DHR-containing multigene family. Genomics 42: 302-310.

Shulman, J.M., N. Perrimon, and J.D. Axelrod. 1998. Frizzled signaling and the developmental control of cell polarity. Trends Genet. (in press).

Siegfried, E., E.L. Wilder, and N. Perrimon. 1994. Components of wingless signalling in Drosophila. Nature 367: 76-80.

Simpson, P., M. El Messal, J. Del Prado, and P. Ripoll. 1988. Stripes of positional homologies across the wing blade of Drosophila melanogaster. Development 103: 391-401.

Slusarski, D.C., V.G. Corces, and R.T. M oon. 1997a. Interaction of Wnt and a Frizzled homolog triggers G-protein-linked phosphatidylinositol signaling. Nature 390: 410-413.

Slusarski, D.C., J. Yang-Snyder, W.B. Busa, and R.T. Moon. 1997b. Modulation of embryonic intracellular Ca2+signaling by Wnt-5A. Dev. Biol. 182: 114-120.

Sokol, S., J. Klingensmith, N. Perrimon, and K. Itoh. 1996. Dorsalizing and neuralizing properties of Xdsh, a maternally expressed Xenopus homolog of dishevelled. Development 121: 1637-1647.

Spradl ing, A. 1986. P el ement-mediated transformation. In Drosophila, A practical approach (ed. D.B. Roberts), pp. 175198. IRL Press, N ew York, NY.
Steitz, S.A., M. Tsang, and D.J. Sussman. 1996. Wnt-mediated relocalization of dishevelled proteins. In Vitro Cell. Dev. Biol.-Animal 32: 441-445.

Strutt, D.I., U. Weber, and M. M lodzik. 1997. The role of RhoA in tissue polarity and Frizzled signalling. Nature 387: 292295.

Sussman, D.J., J. Klingensmith, P. Salinas, P. Adams, R. N usse, and N. Perrimon. 1994. Isolation and characterization of a mouse homolog of the Drosophia dishevelled segment polarity gene. Dev. Biol. 166: 73-86.

Thiesen, H., J. Purcell, M. Bennett, D. Kansagara, A. Syed, and J.L. M arsh. 1994. dishevelled is required during wingless signaling to establish both cell polarity and cell identity. Development 120: 347-360.

Thorpe, C.J., A. Schlessinger, J.C. Carter, and B. Bowerman. 1997. Wnt signal ing polarizes an early $C$. el egans blastomere to distinguish endoderm from mesoderm. Cell 90: 695-705.

Thummel, C.S. and V. Pirotta. 1992. New pCaSpeR P element vectors. Dros. Inf. Serv. 71: 150.

Thummel, C.S., A.M. Boulet, and H.D. Lipshitz. 1988. Vectors for Drosophila P-element-mediated transformation and tissue culture transfection. Gene 74: 445-456.

Tomlinson, A., W.R. Strapps, and J. Heemskerk. 1997. Linking Frizzled and Wnt signaling in Drosophila development. Development 124: 4515-4521.

Torres, M.A., J.A. Yang-Snyder, S.M. Purcell, A.A. DeM arais, L.L. McGrew, and R.T. Moon. 1996. Activities of the Wnt-1 class of secreted signaling factors are antagonized by the Wnt-5A class and by a dominant negative cadherin in early Xenopus development. J. Cell Biol. 133: 1123-1137.

Tsang, M., N. Lijam, Y. Yang, D.R. Beier, A. Wynshaw-Boris, and D.J. Sussman. 1996. Isolation and characterization of mouse dishevelled-3. Develop. Dynamics 207: 253-262.

Vinson, C.R., S. Conover, and P.N. Adler. 1989. A Drosophila tissue polarity locus encodes a protein containing seven potential transmembrane domains. Nature 338: 263-264.

Wong, G.T., B.J. Gavin, and A.P. M cM ahon. 1994. Differential transformation of mammary epithelial cells by wht genes. Mol. Cell. Biol. 14: 6278-6286.

Wong, L.L. and P.N. Adler. 1993. Tissue polarity genes of Drosophila regulate the subcellular location for prehair initiation in pupal wing hairs. J. Cell Biol. 123: 209-221.

Xu, T. and G.M. Rubin. 1993. Analysis of genetic mosaics in developing and adult Drosophila tissues. Development 117: 1223-1237.

Yanagawa, S., F. van Leeuwen, A. Wodarz, J. Klingensmith, and R. N usse. 1995. The dishevelled protein is modified by wingless signaling in Drosophila. Genes \& Dev. 9: 1087-1097.

Yang-Snyder, J., J.R. Miller, J.D. Brown, C.-J. Lai, and R.T. Moon. 1996. A frizzled homolog functions in a vertebrate Wnt signaling pathway. Curr. Biol. 6: 1302-1306.

Zeng, L., F. Fagatto, T. Zhang, W. Hsu, T.J. Vasicek, W.L. Perry III, J.J. Lee, S.M. Tilghman, B.M. Gumbiner, and F. Costantini. 1997. The mouse Fused locus encodes Axin, an inhibitor of the Wnt signaling pathway that regulates embyronic axis formation. Cell 90: 181-192.

Zwaal, R.R., J. A hringer, H.G.A.M. van Luenen, A. Rushforth, P. Anderson, and R.H.A. Plasterk. 1996. G proteins are required for spatial orientation of early cell cleavages in C. elegans embryos. Cell 86: 619-629. 


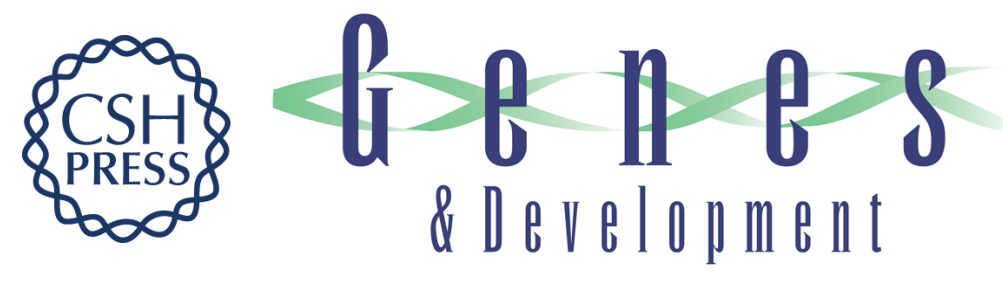

\section{Differential recruitment of Dishevelled provides signaling specificity in the planar cell polarity and Wingless signaling pathways}

Jeffrey D. Axelrod, Jeffrey R. Miller, Joshua M. Shulman, et al.

Genes Dev. 1998, 12:

Access the most recent version at doi:10.1101/gad.12.16.2610

References

This article cites 67 articles, 32 of which can be accessed free at: http://genesdev.cshlp.org/content/12/16/2610.full.html\#ref-list-1

License

Email Alerting

Receive free email alerts when new articles cite this article - sign up in the box at the top Service right corner of the article or click here.

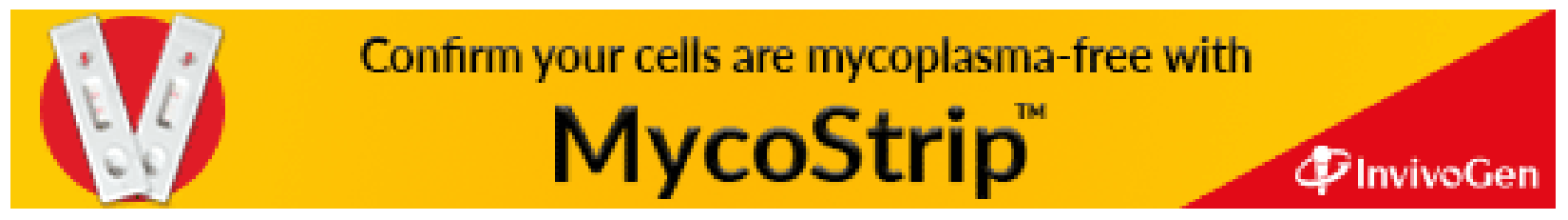

